\title{
PRODUÇÃO, PRODUTIVISMO, PLÁGIO: CONSIDERAÇÕES SOBRE A ORIGINALIDADE NA PESQUISA EM ENSINO DE LÍNGUAS
}

\author{
Thomas Massao FAIRCHILD ${ }^{1}$
}

\begin{abstract}
Resumo: Procuramos contribuir para a compreensão da universidade contemporânea analisando a noção de "originalidade" construída em práticas de pesquisa atuais. Partimos de uma problematização do plágio, argumentando que a emergência de debates a esse respeito pode estar sinalizando um aumento da tolerância à reprodução do conhecimento por meio do estabelecimento de formas "corretas" de se reproduzir pesquisas existentes. Procuramos dar tratamento teórico ao problema da "originalidade", em seguida, retomando as discussões de Pêcheux (1995) acerca da "evidência do sentido" e do "préconstruído”. Valemo-nos desses conceitos para analisar enunciados de uma dissertação de mestrado; mostramos que essa pesquisa está organizada de forma a preservar o "préconstruído" de um discurso teórico mesmo quando os dados o contradizem. Perguntamonos como o trabalho é considerado "original” nessas condições. Esboçamos uma resposta dando ao discurso uma abordagem "econômica”, com base em Bourdieu (1998) e Zizek (2011). Apresentamos a tese de que o valor de "originalidade" da pesquisa, no contexto de um produtivismo protegido pelo Estado, pode ser produzido de forma especulativa por grupos que exercem um controle parcial dos processos de "apreciação" dos enunciados científicos.
\end{abstract}

Palavras-chave: Produção de conhecimento. Produtivismo. Plágio. Mercado. Análise do Discurso.

Neste trabalho, discutimos os modos de produção de conhecimento na universidade contemporânea a partir de uma problematização acerca da “originalidade” na pesquisa acadêmica. Situamos nossos argumentos no campo do ensino de línguas e da

\footnotetext{
${ }^{1}$ UFPA - Universidade Federal do Pará - Instituto de Letras e Comunicação. Belém - Pará - Brasil. 66075110 - tmfairch@yahoo.com.br.
} 
formação de professores, não só porque nossa experiência está inscrita nele, mas porque entendemos que a pesquisa nesse contexto está sujeita a condições que não permitem tomá-la como mero reflexo de um movimento que atinge a universidade como um todo. Procuramos responder às seguintes perguntas: a) o que é "produzir conhecimento" quando o objeto de pesquisa é o ensino de uma língua?; e b) de que forma as transformações recentes na universidade estão modificando também o regime de “conhecimento” até então vigente no campo do ensino de línguas?

A discussão desenvolvida aqui insere-se no projeto de pesquisa "A escrita sobre as práticas de ensino em licenciaturas do Brasil, da Costa Rica e de Honduras: registro, análise e produção de conhecimento” (CNPq 458449/2014-8), por meio do qual vimos discutindo como se configuram as relações entre escrita, docência e conhecimento nas práticas de formação de professores. Procuramos contribuir para esse projeto apresentando, aqui, a discussão de alguns procedimentos argumentativos/interpretativos encontrados em um texto de pesquisa sobre o ensino de uma língua estrangeira que podem indiciar transformações importantes nas relações entre esses três elementos. Como se trata de uma dissertação de mestrado defendida e aprovada em data recente, consideramos que sua análise é válida para se descrever os processos de produção de conhecimento que estão sendo legitimados no campo.

O trabalho estrutura-se em quatro seções. Na primeira, circunscrevemos o problema da “originalidade” em pesquisa a partir de uma reflexão sobre a emergência do plágio enquanto objeto de debates na universidade brasileira. Na segunda, esboçamos uma abordagem teórica da "originalidade” em pesquisa, retomando para tanto algumas considerações de Michel Pêcheux (1995) e confrontando-as com nossa própria leitura do campo do ensino de línguas no Brasil. Na terceira, apresentamos a análise de alguns procedimentos interpretativos presentes em uma dissertação de mestrado, mostrando que seus resultados frustram a expectativa produzida pela escolha inicial de uma perspectiva teórica. Na quarta seção, esboçamos uma hipótese de cunho “econômico” sobre o processo que pode estar sustentando a legitimação de conclusões contraditórias com os dados, atribuindo-lhe um valor de “originalidade” a despeito de seus dados mostrarem o contrário do que se afirma sobre eles. 


\section{Se não é cópia, então... é original?}

A intensificação de políticas voltadas ao incremento da produtividade acadêmica, nos últimos anos, aconteceu de forma simultânea a um avivamento das discussões sobre o plágio na universidade. Não se trata de coincidência. Esses movimentos parecem estar indicando transformações mais abrangentes nas práticas de pesquisa, nas formas de escrita e divulgação de conhecimento e mesmo em noções como as de autoria e originalidade a que estávamos habituados dentro de um determinado modelo universitário.

Nossa hipótese é que o debate sobre o plágio vem crescendo na medida em que, a fim de aumentar a "produtividade” acadêmica, passou a ser importante definir não apenas as práticas de escrita que serão banidas, mas também quais serão aceitas. A emergência dos debates sobre o plágio, sob esse ponto de vista, se mostra útil para atender a uma demanda específica: legitimar novos parâmetros de produtividade que requerem um aumento da tolerância à reprodução e um alargamento dos critérios pelos quais se define o que é “original” em pesquisa. Apenas na medida em que haja certo risco de se confundir o "produtivo" com o "fraudulento” é que se torna imperativo esmiuçar a mecânica do plágio.

A passagem a seguir, embora corajosa e muito direta, exemplifica como, mesmo dentro de uma crítica à ideologia do produtivismo acadêmico, a discussão sobre o que é produzir conhecimento se mantém num plano secundário em relação ao que se consideram “más práticas”.

Esses [desdobramentos do produtivismo acadêmico] vão desde a instalação de climas de rivalidade e disputa entre colegas, acompanhada de uma busca cada vez mais frenética e desmedida por espaços editoriais qualificados por parte daqueles que estão nas universidades e outras instituições ligadas à produção do conhecimento, passando pela adoção acrítica dos mesmos critérios das ditas ciências duras - com maior tradição de publicar em periódicos e com pesquisa de caráter mais universal - para as ciências humanas e sociais (que produzem num outro ritmo) até a multiplicação das revistas inconsistentes. [...] No Brasil e em várias partes do mundo, são crescentes os casos envolvendo más condutas em pesquisas científicas, como: manipulação, falsificação ou fabricação de dados ou de resultados, plágio, autoplágio (apresentação total ou parcial de textos já publicados pelo mesmo autor como se fossem inéditos), bem como a prática - bastante comum, diga- 
se de passagem - da coautoria de fachada. (REGO, 2014, p. 328-338, grifo nosso)

Ao levantar alguns problemas (verdadeiros), a autora desta passagem ao mesmo tempo cria, por um efeito de linguagem bem conhecido dos semanticistas ${ }^{2}$, uma série de “espantalhos” cujo papel acaba sendo o de resguardar a "verdadeira” academia de questionamentos. Ao se dizer que existem, por exemplo, “revistas inconsistentes”, faz-se acreditar, por tabela, que haveria "revistas consistentes" e, mais ainda, que o fato de se poder demonstrar a inconsistência de uma revista levaria à conclusão de que tem que haver outras mais consistentes. Há nisso alguma verdade, sem dúvida - mas sob um ângulo muito particular. Esse argumento afasta a possibilidade de conceber que o problema do produtivismo seja o modo de produção e não apenas a "má produção". Não se põe em dúvida a conduta dos que ocupam os espaços “qualificados” - apenas a dos que estão fora deles, tentando atabalhoadamente entrar. Quanto mais se toma a “pseudoacademia” como objeto de regulação, sob esse prisma, mais se dá a entender que a ciência “verdadeira” e as "boas condutas” estariam acima da necessidade de um controle semelhante. Questiona-se (legitimamente) a originalidade dos textos que plagiam - mas o que temos a dizer sobre a originalidade dos textos que estão sendo plagiados?

Nos casos em que a crítica ao plágio arrisca-se a mostrar concretamente uma alternativa, tem-se uma amostra um pouco mais concreta da concepção de produtividade subjacente ao debate. A título de exemplo: circulou por e-mail, em anos recentes, um documento que se apresentava como “cartilha” visando esclarecer estudantes universitários sobre o que é o plágio. O documento foi elaborado por uma comissão encarregada de avaliar casos de autoria controversa em uma universidade federal brasileira. Embora o documento resulte de uma iniciativa louvável, a concepção do que seria um trabalho “original” apresentada como contraponto do que seria "plágio” é suscetível a algumas críticas que raramente são levantadas. Comecemos lendo um trecho do texto apresentado como exemplo de plágio:

\footnotetext{
2 Nos referimos, de forma ampla, aos problemas tratados por Ducrot (1987) com os conceitos de pressuposição e de subentendido, dos quais vemos um exemplo aqui. Se digo "João fez uma má escolha", subentendo que havia escolhas melhores a sua disposição. Veremos na segunda parte que se trata de um problema teórico semelhante ao do “pré-construído” em Pêcheux (1995).
} 
Em outras épocas, os dilemas existenciais eram mais simples que atualmente. Na modernidade, a questão subjetiva central girava em torno de um pensamento como algum dia formar uma família e chegar à diretoria de uma empresa. Atualmente, diversificam-se os ideais.

A “pós modernidade” significa uma postura do indivíduo (pensamentos e ações)...

Agora o texto na forma recomendada pela cartilha (sem plágio), com destaques nossos:

Como aponta Bauman (2009, p. 155), em outras épocas, os dilemas existenciais eram mais simples que atualmente, quando diversificam-se os ideais. Na modernidade, a questão subjetiva central girava em torno de um pensamento como algum dia formar uma família ou chegar à diretoria de uma empresa. Agora, o indivíduo passa a poder escolher também se quer formar uma família de forma independente, valendo-se das inovações científicas de reprodução humana, e em quais países gostaria de trabalhar, sendo que estas opções já não serão as mesmas dentro de pouco tempo. A passagem a seguir esclarece ainda mais essa questão:

"Se desde a época do 'desencaixe' e ao longo da era moderna, dos 'projetos de vida', o 'problema da identidade' era a questão de como construir a própria identidade [...]” (BAUMAN, 2009, p. 155) A "pós modernidade" significa uma postura do indivíduo (pensamentos e ações)...

O segundo texto realmente parece melhor que o primeiro, mas esse efeito resulta, em parte, de que a segunda versão é necessária para apontar onde está o plágio na versão anterior. Se considerarmos o texto recomendado em si mesmo, notaremos que, embora ele credite devidamente suas fontes, nem por isso consiste em um texto original: encontrase nele, ainda, uma paráfrase das ideias de Bauman. Disso se pode depreender que, ao menos nesse caso, está-se considerando o plágio como uma forma errada de se citar um autor, situando o problema no nível da superfície textual e não no da concepção do trabalho em si.

Essa perspectiva contém, a nosso ver, uma falha. O exemplo acima deixa claro que o texto sem plágio pode ser obtido a partir do texto com plágio por meio de acréscimos de natureza técnica, como a inclusão do sobrenome do autor seguido da data de publicação da obra citada e do número da página de onde a citação foi extraída. Embora se possa argumentar que uma mudança dessa ordem faz toda diferença, não deixa de surpreender que nada se diga sobre a passagem iniciada por “em outras épocas...” até 
“...diretoria de uma empresa”, na qual se encontra o conteúdo do texto propriamente dito, e que permanece idêntica nas versões com plágio e sem plágio. Usando um pouco de imaginação, poderíamos pensar que o texto 1, passível de denúncia por plágio, poderia ser transformado no texto 2 graças à intervenção de um revisor técnico ou do orientador - se fosse esse o caso, teríamos promovido uma mudança na forma como o autor citante se apropria das ideias alheias ${ }^{3}$ ?

As passagens em que as diferenças entre as duas versões são mais substantivas não ajudam a contornar esse problema, pois elas consistem em acréscimos arbitrários (todo o segundo trecho negritado é um exemplo). Essas partes poderiam ser retiradas da segunda versão sem que o problema do plágio reaparecesse, o que mostra que a ausência de crédito ao autor não é a única variável sendo manejada ao se transformar o primeiro texto no segundo. Poderíamos, inclusive, discutir em que medida esses acréscimos “melhoram” o texto. O trecho parafraseado no primeiro parágrafo torna-se mais longo na segunda versão, sendo acrescido inclusive de uma citação direta, o que poderia ser interpretado como um aumento da quantidade de material alheio presente no texto - e, consequentemente, como uma diminuição do seu teor de originalidade.

Parece-nos sensato supor, com base nesse exemplo, que ao menos uma parte dos problemas de plágio que enfrentamos tem a ver com a dificuldade de demonstrar o que seria um texto original. De algum modo, combatendo uma forma de mau uso da palavra alheia, estimula-se outra muito parecida. É nesse sentido que o recrudescimento dos debates sobre a fraude acadêmica pode ser sugestivo de uma escassez de originalidade e de uma fragilização generalizada da autoria, não nas pesquisas "más”, oriundas da “pseudoacademia”, mas no próprio modo de produção que vem sendo legitimado na universidade.

Nas seções subsequentes apresentamos uma parte de nossos esforços para avançar na crítica dos modos de produção de conhecimento que vêm sendo validados pela universidade contemporânea, particularmente no campo das pesquisas sobre o ensino de línguas.

\footnotetext{
${ }^{3}$ Na verdade, o exemplo é válido mesmo se pensarmos que o próprio autor introduza as modificações sugeridas. Não é um exemplo à toa porque uma das soluções comuns para casos de plágio é a introdução de uma errata com indicações semelhantes às que são recomendadas na cartilha de que estamos falando. Se o texto era considerado fraudulento por apresentar uma ideia sem dizer que essa ideia já tinha sido elaborada por outra pessoa antes, ele se torna original por apresentar a mesma ideia, apenas dizendo explicitamente que é de segunda mão?
} 


\section{Seria uma novidade - se ninguém tivesse pensado antes...}

Em Semântica e Discurso, Pêcheux (1995) procura dar conta de um problema central: o efeito de evidência do sentido que recobre a circularidade e a autorreferencialidade de um discurso. Alguns de seus apontamentos são úteis para construir, de um ponto de vista teórico, uma noção do que seja escrever um texto de pesquisa “original”, ao qual se possa creditar a produção de um conhecimento.

Lembremos como ele retoma o problema das orações relativas (adjetivas) na filosofia da linguagem. Pêcheux (1995, p. 95) serve-se de um exemplo de Frege: “aquele que descobriu a forma elíptica das órbitas planetárias morreu na miséria”. Para Frege, uma frase como essa carrega um efeito ilusório produzido pela própria língua; seu raciocínio é que a expressão "aquele que descobriu a forma elíptica das órbitas planetárias” produz uma “denotação”, fazendo-nos entender “Kepler”, ao mesmo tempo em que nos “obriga” a pensar: a) que as órbitas planetárias são mesmo elípticas; e b) que foi mesmo Kepler quem fez essa descoberta. O problema é que a denotação não tem um valor de verdade, mas apenas indica um referente. Assim, por exemplo, a negativa da mesma frase ("aquele que descobriu a forma elíptica das órbitas planetárias não morreu na miséria”) mantém a denotação incólume - continuamos entendendo que a frase faz uma afirmação sobre Kepler -, bem como permanece intocado o domínio das duas asserções implícitas na oração relativa. Para que essas asserções adquiram um valor de verdade passível de ser aceito ou contestado, seria preciso expressá-las por meio de orações independentes, como “as órbitas planetárias (não) são elípticas” ou "Kepler (não) descobriu a forma elíptica das órbitas planetárias”. A análise de Frege mostra que há, portanto, um “domínio de pensamento” anterior e sobreposto ao “pensamento” expresso pelo conjunto do enunciado que faz uma afirmação sobre as condições financeiras de Kepler no fim de sua vida. Para ele, trata-se de um problema, e sua causa seria o caráter falho da própria língua. Pêcheux (1995, p. 98-99) diverge:

[...] a 'ilusão" de que fala Frege não é o puro e simples efeito de um fenômeno sintático que constitui uma 'imperfeição da linguagem': o fenômeno sintático da relativa determinativa é, ao contrário, a condição formal de um efeito de sentido cuja causa material se assenta, de fato, na relação dissimétrica por discrepância entre dois "domínios de pensamento", de modo que um elemento de um domínio irrompe num 
elemento do outro sob a forma do que chamamos "pré-construído", isto é, como se esse elemento já se encontrasse aí.”

Com isso, Pêcheux está mostrando que o discurso não funciona apenas como algo que permite construir proposições sobre objetos ou temas recortados do mundo “empírico”, mas também como um sistema que constantemente faz referência a si mesmo. A existência do “pré-construído” atesta que alguns enunciados podem ser particularmente capciosos ao pressupor uma informação sobre a qual se poderia divergir, mas também, e acima de tudo, que um discurso só é interpretável na medida em que pode ser "lido" dentro de uma série histórica. A novidade de Pêcheux, nesse sentido, não está tanto em apontar o "pré-construído” (já bastante explorado na filosofia da linguagem), mas em estender as consequências que tira daí para uma concepção geral do discurso.

O aspecto conflitante dos diferentes “domínios de pensamento” expressos em uma mesma preposição, segundo essa perspectiva, cumpre o papel epistemológico de flagrar um processo que, em enunciados aparentemente mais homogêneos, estaria agindo da mesma forma. A frase “aquele que descobriu a forma elíptica das órbitas planetárias morreu na miséria” seria tão problemática quanto seu possível equivalente, “Kepler morreu na miséria”, na medida mesmo em que “Kepler”, como nome próprio, ou qualquer outra expressão que viesse a substituir esse termo dentro da formação discursiva, teria que ser entendido como elemento responsável por uma “denotação” e pelo acionamento de um "pré-construído"4.

O mesmo se aplica aos próprios enunciados de uma ciência: se digo “o golfinho é um mamífero”, não estaria fazendo mais que postular uma regra - "tudo aquilo que for animal e amamentar as crias poderá ser designado pela palavra 'mamífero'”. Com isso, desvendo uma propriedade do mundo empírico ou explicito um acordo implícito no discurso da Biologia? Mais ainda: o enunciado “o golfinho é um mamífero” nada mais é que uma paráfrase possível para uma proposição mais claramente circular, como "o golfinho, que é um animal que amamenta suas crias, pertence à classe dos mamíferos, que

\footnotetext{
${ }^{4}$ Para termos um exemplo mais próximo ao tema que nos interessa, uma expressão como "aula tradicional”, muito comum em textos que tratam do ensino de línguas, tem seu "pré-construído" evidenciado quando a comparamos com expressões recortadas de outras formações discursivas, como "cozinha tradicional" ou "cultura tradicional", nas quais a palavra "tradicional" adquire uma conotação positiva. O fato de a estrutura sintática da expressão ser extremamente simples (determinante-determinado) e idêntica nos três casos apenas reforça a tese de que o sentido de um enunciado provém de um certo jogo de ecos com outros enunciados.
} 
são animais que amamentam suas crias”, ou num caso extremo, “o animal que amamenta suas crias pertence à classe dos animais que amamentam suas crias”. E se aquele que descobriu a forma elíptica das órbitas planetárias não tiver descoberto a forma elíptica das órbitas planetárias, mas copiado os resultados da pesquisa de um colega que por qualquer razão nunca veio à luz para incriminá-lo, ainda será Kepler? Ou deixará de sêlo, mantendo apenas o mesmo nome - tornando todos os enunciados em que esse nome já foi usado subitamente controversos?

É evidente que nesses exemplos estamos tratando de "regras" bastante simplificadas e qualquer discurso real estaria assentado em princípios mais complexos. Ainda assim, a noção fundamental apontada por Pêcheux é a de que um discurso não se caracteriza apenas pela particularidade das regras nas quais se assenta - que, se objetivadas, pareceriam estranhas ou absurdas - mas por distribuir os elementos sujeitos a essas regras de forma assimétrica. O “novo” não estaria relacionado ao desvendamento de um elemento desconhecido do real nem à descoberta de novas relações entre elementos conhecidos - ele seria um efeito da repartição entre o implícito e o explícito de um discurso, ou melhor dizendo, entre as proposições que se inscrevem como "préconstruído" do discurso e aquelas que se colocam num espaço de mobilidade relativa, sujeitas a um trabalho de ajustamento com o real (na forma da produção de dados, por exemplo) e de encadeamento com elementos anteriores do discurso (na forma de argumentação, demonstração, refutação e inclusive citação etc.).

Pêcheux chega a denominar essa autorreferencialidade do discurso de "efeito Munchhausen”, fazendo referência ao personagem conhecido por contar histórias mirabolantes e, em especial, a um episódio em que este afirma ter se içado para fora da areia movediça puxando-se para cima pelos próprios cabelos. Pêcheux também se refere várias vezes à personagem La Palice (inclusive, no título original da obra), que figura em trovas populares cujo efeito de humor está em jogar com as tautologias implícitas de certas afirmações - “desposou-se, conta-se / uma virtuosa senhora / se tivesse continuado solteiro / não teria tido esposa. / Foi sempre querido / ela não era ciumenta / desde que se fez seu marido / ela se fez sua esposa” (PECHEUX, 1995, p. 36).

Essa argumentação de Pêcheux consiste, evidentemente, numa séria ameaça a qualquer discurso científico. Até certo ponto há nisso um alerta válido - Pêcheux não é o 
único a sugerir que as ciências, ao menos em algumas de suas etapas, andam em círculos ${ }^{5}$. Nem todo enunciado científico, no entanto, resulta de um “efeito Munchhausen” - se assim fosse, seria difícil explicar como os próprios discursos científicos se modificam, como surgem novas ciências.

O próprio Pêcheux esboça uma explicação, à qual nos ateremos aqui. Dentro de um dado campo epistemológico, no qual se encontra um complexo de "ideologias teóricas”, determinados elementos podem funcionar, segundo as circunstâncias, como “obstáculos epistemológicos” para o avanço científico ou como matéria-prima para o mesmo movimento. Tomemos um exemplo: o conceito de "lesão funcional” foi elaborado por psiquiatras franceses na segunda metade do século XIX para explicar a origem da histeria a partir do momento em que se admitiu que, em pelo menos alguns casos, era impossível detectar uma lesão "real” como causa da doença. A ausência de uma lesão detectável representava um "obstáculo” do ponto de vista médico, ao mesmo tempo em que operou como “matéria prima” para a elaboração das primeiras teses psicanalíticas por Freud (ALLOUCH, 1995). Se quisermos um exemplo mais próximo, podemos pensar em uma frase como "lá é gostoso", na qual um advérbio parece ocupar a posição de sujeito (FRANCHI, 2006) - a análise sintática deste caso pode mostrar-se como um “obstáculo epistemológico” que emperra o aparato epistemológico canônico, mas ao mesmo tempo como “matéria prima” para a produção de uma teoria, ainda inexistente, que pode vir a explicar ocorrências desse tipo.

Para Pêcheux (1995, p. 193), “o momento histórico do corte que inaugura uma ciência dada é acompanhado necessariamente de um questionamento da forma-sujeito e da evidência do sentido que nela se acha incluída”. Os exemplos que demos podem ser interpretados como casos que levam ao estranhamento de uma obviedade produzida pelo discurso - que toda doença deve ser causada por algum tipo de afecção orgânica, ou de que um advérbio não possa exercer determinadas funções sintáticas. Não se trata de saber qual é a origem da histeria, nem de se saber como analisar uma frase inusitada, mas de reconhecer que elas comprometem alguma parte do "pré-construído" que sustenta o discurso dentro do qual tomamos esses elementos como dados e apontam para a

\footnotetext{
${ }^{5}$ Sobre isso, veja-se, por exemplo, a argumentação de Kuhn sobre a "ciência ordinária" - especialmente a noção de "resolução de quebra-cabeças": "Talvez a característica mais impressionante dos problemas normais da pesquisa [...] seja seu reduzido interesse em produzir grandes novidades, seja no domínio dos conceitos, seja no dos fenômenos” (KUHN, 1978, p. 57).
} 
potencialidade de um discurso futuro, do qual se entrevê apenas uma silhueta incompleta, por assim dizer. O conhecimento, sob esse prisma, não resulta da confirmação de uma hipótese, da observação de um experimento, da consolidação de um corpus ou mesmo da revisão intencional de uma teoria - ele advém do trabalho do "impensado no pensamento" e emerge, ao menos inicialmente, como um "processo sem sujeito".

Estamos designando aqui o trabalho do impensado no pensamento, por meio do qual os próprios termos de uma questão, com a resposta que ela pressupõe, desaparecem, de modo que a questão perde literalmente o sentido, ao passo que vão se formando 'respostas' novas a questões que não haviam sido colocadas - processo no qual nomes e expressões se apagam, com a referência 'evidente' a seus objetos, enquanto outros nomes e expressões aparecem sob o efeito de certos deslocamentos do campo, de certas intrusões 'incongruentes' de elementos 'lançados', desligados-caídos de outros lugares '[...]. (PECHEUX, 1995, p. 194)

Com essa definição, pode parecer que Pêcheux se refere a situações de “crise” de uma ciência e a pontos de emergência de novas discursividades; a questão realmente é posta, nesse momento de sua obra, como concernente à fundação de uma ciência materialista, de base marxista - um projeto ambicioso. Não nos parece que, por essa razão, suas considerações devam ser pensadas como estranhas às ações mais cotidianas de pesquisa - trata-se de pensar em que medida, mesmo em investigações de menor escopo, pode-se entregar os rumos do trabalho à "evidência do sentido" ou manter os estranhamentos encontrados no percurso como questões abertas. Essas posturas nos parecem particularmente relevantes quando se pensa na relação do pesquisador com os dados que coleta em campo, com as interpretações que já são possíveis para esses dados e com os aspectos de seus dados que podem causar conflito com essas interpretações antecedentes. O trabalho analisado na seção a seguir será discutido dentro dessa chave de leitura.

\section{Vamos ouvi-los... mas que não venham com bobagens!}

Apresentamos agora a análise de alguns procedimentos argumentativos/interpretativos encontrados em uma dissertação de mestrado que trata do ensino de uma língua estrangeira. Por razões já mencionadas, consideramos que se trata de um texto representativo daquilo que, dentro do funcionamento atual do campo do 
ensino de línguas, é considerado um percurso válido de investigação de um problema, interpretação de resultados e acréscimo ao repertório de conhecimentos da área.

A pesquisa consiste numa investigação de um professor universitário sobre suas próprias práticas enquanto formador de professores de inglês em um curso de licenciatura. Nossa análise não consiste numa revisão do trabalho ponto a ponto. Nosso procedimento foi, a partir de sua leitura, destacar alguns enunciados que ilustram o funcionamento da formação discursiva "dominante” na qual o discurso se inscreve. Chegamos a três pares de "proposições” que ilustram dois “domínios de pensamento" contraditórios inscritos em um mesmo complexo discursivo. O ponto central de nossa análise consiste em demonstrar como os enunciados de um desses domínios, que aparecem como potenciais “obstáculos epistemológicos”, são neutralizados pelos enunciados do outro (isto é, pela forma-sujeito da teoria), que os reinterpreta ou recusa, devolvendo ao discurso a “evidência de sentido”. Vejamos esses pares de enunciados um por um.

Primeiro par: o trabalho apresenta como justificativa e, em certa medida, como razão de sua originalidade (em relação a outras pesquisas sobre o mesmo tema), o fato de inscrever-se em uma determinada linha teórica:

(1a) A perspectiva adotada neste trabalho foca-se na ideia de que os alunos são agentes do processo de avaliação formativa. Essa perspectiva parte da constatação de que nem sempre o professor pode garantir a regulação dos processos de aprendizagem dos alunos. Apenas aquele que está aprendendo pode, realmente, ajustar suas estratégias de aprendizagem. Dessa maneira, na avaliação formativa de base cognitivista, a regulação é considerada o centro do processo, e sobretudo a regulação realizada pelo aluno, que recebe o nome de autorregulação.

Esta passagem provém de uma seção do texto em que o autor discorre sobre as diferenças entre duas correntes da "avaliação formativa”: uma de origem anglo-saxônica, cujo foco estaria na noção de “feedback" e nas decisões tomadas pelo professor (“regulação”), e outra de origem francófona, cujo foco estaria nas ações do próprio aluno, na forma como ele aprende e percebe sua aprendizagem (“autorregulação”). O argumento do autor é o de que, embora a "avaliação formativa” seja uma perspectiva comum nos trabalhos da área, sua pesquisa se destacaria por inserir-se na abordagem francófona e conferir um papel central aos alunos, tanto na condução das atividades em aula (trata-se de pesquisa-ação) como na interpretação dos efeitos do processo de ensino-aprendizagem 
(por exemplo, os alunos seriam ouvidos sobre o que aprenderam, em vez de serem avaliados exclusivamente a partir das premissas do professor).

Embora a perspectiva teórica adotada postule uma primazia da “autorregulação” sobre a "regulação", no entanto, a pesquisa situa em um gesto do professor a condição para que os alunos se "autorregulem":

(1b) A constatação de que a avaliação tradicional é predominante no curso levou-me a implantar a avaliação formativa em minhas próprias práticas como formador de professores em um curso de licenciatura em Inglês como Língua Estrangeira. Compreendi que trabalhar com a avaliação formativa seria uma maneira de o aluno autoavaliar e autorregular suas aprendizagens, aperfeiçoando suas competências linguageiras na língua alvo, além de permitir-lhe vivenciar uma experiência que ele mesmo, posteriormente, poderia replicar com suas turmas, na posição de professor.

A mudança de uma avaliação "tradicional” para uma perspectiva centrada na “autorregulação”, com efeito, é atribuída a um gesto inaugural do professor (“me instigou”), que se assume explicitamente como sujeito do ato de instaurar a avaliação formativa (“em minhas próprias práticas”). Na frase seguinte, o verbo "trabalhar [com a avaliação formativa]” aparece numa forma nominal sem um sujeito explícito, de modo que não é claro qual seria o agente desse ato; pode-se interpretá-lo como sendo o professor, os alunos ou ambos - por um efeito de paralelismo, parece mais provável que se trate do professor. Ainda na mesma frase, é certamente o aluno que figura como agente dos atos de “autoavaliar” e "autorregular”, porém, um pouco adiante, explicita-se que o ato do professor "permite” ao aluno proceder dessa forma. Finalmente, o papel do professor como instaurador da "autoavaliação" no aluno é apresentado como um mandato transmissível: é preciso que o professor trabalhe dessa forma para que o aluno, ingressando posteriormente no magistério, tenha a possibilidade de atuar da mesma forma.

Todo este parágrafo, apesar do que se diz explicitamente sobre a primazia do aluno, assenta-se num “pré-construído” que deveria ser, em rigor, estranho à própria perspectiva adotada. Se “apenas aquele que está aprendendo pode, realmente, ajustar suas estratégias de aprendizagem”, como lemos em (1a), por outro lado, aquele que está aprendendo só pode começar a ajustar suas estratégias de aprendizagem na medida em que o professor ajuste primeiro suas práticas de ensino (1b). A própria suposição de que 
a validade da pesquisa esteja em suscitar um comportamento semelhante nos futuros professores baseia-se na pressuposição de um aluno que se espelha em seu mestre de forma bastante determinista. Isso quer dizer que, mais ou menos como nos exemplos discutidos por Pêcheux, tem-se aqui uma proposição apresentada como sendo “nova” (a pesquisa enfoca o processo de aprendizagem do aluno), que se assenta por sua vez em um “domínio de pensamento” antecedente, no qual se encontra um postulado a princípio assimétrico. A forma como esse "pensamento" antecedente se integra ao sentido geral do discurso é semelhante àquela vista nas orações relativas - negar que o professor tenha trabalhado segundo os preceitos de uma avaliação formativa não consiste, necessariamente, numa negação de que caiba ao professor provocar a "autorregulação" nos alunos.

Eis, portanto, um primeiro par de enunciados contraditórios, que podemos formular do seguinte modo: a autonomia do aluno... depende da permissão do professor. Vamos agora ao segundo par.

(2a) Nosso objetivo foi perceber como os alunos lidavam com os processos de autoavaliação, especialmente quais eram os objetos de sua autoavaliação. Queríamos saber o que eles avaliavam quando avaliavam seu desempenho, uma vez que acreditamos que os objetos de avaliação que eles mencionam são os que eles acreditam que sejam mais relevantes para a sua aprendizagem.

Neste trecho, o autor apresenta seu objetivo principal na pesquisa, que é condizente com as afirmações vistas em (1a) e, de modo geral, com sua filiação à perspectiva francófona da "avaliação formativa". Ao longo da pesquisa, o autor afirma ter desenvolvido diversas atividades que visavam estimular os alunos a se autoavaliarem, dentre elas, a construção de um "roteiro de autoavaliação" e a tarefa de produzir um “diário de aprendizagens”. Essas atividades forneceram dados que respondem ao objetivo postulado em (2a), porém a resposta encontrada não é condizente com as expectativas do autor:

(2b) [...] um aluno menciona apenas a pronúncia em inglês como a competência que considera decisiva para melhorar suas habilidades de speaking, o que não é apropriado, visto que muitos outros planos estão envolvidos nessa habilidade. Apesar disso, o fato de o aluno notar que certo cantor é mais fácil de entender do que outros e utilizar 
suas canções para treinar não deixa de ser relevante para o processo de autorregulação.

Aqui, o posicionamento assumido pelo pesquisador ante seus dados é condizente com o "domínio de pensamento" visto em (1b), no qual se reserva ao professor a prerrogativa de instigar (ou impedir) a autonomia dos alunos. Essa postura se manifesta no fato de que, embora afirmando que "os objetos de avaliação que [os alunos] mencionam são os que eles acreditam que sejam mais relevantes para a sua aprendizagem" (2a), o autor discorda de que os objetos de avaliação mencionados pelos alunos sejam realmente relevantes para a aprendizagem deles. A ressalva constante do segundo período do trecho (2b) não desfaz essa assimetria, uma vez que ela pode ser interpretada como resultante do fato de o autor concordar com a medida tomada pelo aluno e não de estar dando à avaliação do aluno um peso maior do que à sua própria, como professor. Temos, portanto, um segundo par contraditório: a pesquisa procura esclarecer os critérios de avaliação dos alunos... mas os critérios deles não são bons.

O terceiro e último par de proposições inter-relacionadas tem a ver com o modo como o autor procura explicar o resultado do seu trabalho:

(3a) $\mathrm{O}$ fato de as competências linguísticas serem objeto de autoavaliação com mais frequência pode ter a ver com o fato de a gramática ser tradicionalmente enfatizada no ensino de línguas estrangeiras. Por exemplo, na autoavaliação dos alunos sobre a atividade de elaboração de um diálogo em duplas, eles fizeram comentários sobre a pronúncia e, em especial, os verbos.

Novamente, temos em (3a) uma hipótese que, se não é realmente investigada na pesquisa, é plenamente compatível com a perspectiva delineada em (1a) e (2a): são os estudantes que, a partir de suas experiências, elegem seus critérios de autoavaliação e constroem seus objetivos de aprendizagem - que podem ou não coincidir com os critérios e objetivos do professor. Mais uma vez, também, esse “domínio de pensamento” é interceptado por um “pré-construído” que o desloca significativamente. Vejamos o que o autor diz nas conclusões de seu trabalho:

(3b) As atividades didáticas que favoreceram a autoavaliação e autorregulação [...] [consistem em] atividades didáticas que vão além da competência linguística, que proporcionam ao aluno apenas a prática mecânica de estruturas gramaticais, e que frequentemente são a 
única proposta nas aulas de língua estrangeira. [...] As atividades que favoreceram a autoavaliação e a autorregulação, foram: coavaliação, avaliação mútua, roteiro de autoavaliação, diário de aprendizagem, elaboração de objetivos comunicativos, elaboração de critérios avaliativos.

É notável que, apesar do que é dito em (3a), o ensino de gramática e as atividades do livro didático adotado no curso não sejam mencionados entre as atividades que fomentaram a autoavaliação, ainda que o autor tenha constatado que o objeto de autoavaliação mais mencionado pelos alunos sejam as competências linguísticas e ele mesmo (o autor) atribua esse fato ao ensino de gramática. Deve-se observar também que as atividades apontadas em (3b) como sendo mais favoráveis à autoavaliação e à autorregulação são aquelas preconizadas pela perspectiva teórica adotada pelo pesquisador, muito embora os dados provenientes da pesquisa de campo não mostrem que elas tenham provocado um efeito notável. Temos, portanto, um terceiro par contraditório: os alunos tendem a autoavaliar suas competências linguísticas... mas o ensino das competências linguísticas não fomenta a autoavaliação.

Estas considerações parecem suficientes para demonstrar que a pesquisa relatada se assenta sobre uma espécie de diálogo que opera internamente à formação discursiva dominante. Ela ilustra uma situação peculiar do fazer científico, que pode ser caracterizada por dois movimentos sucessivos: a) os dados obtidos em campo, e parte da própria interpretação inicial que o pesquisador faz deles, estabelecem uma contradição com o “pré-construído” do discurso teórico, erigindo-se em potencial “obstáculo epistemológico” e ensejando um questionamento da "evidência de sentido” do discurso dominante; b) essa contradição, no entanto, é absorvida pela forma-sujeito do discurso dominante, ainda que às custas de uma argumentação explicitamente falha (de um ponto de vista formal), como forma de preservar a "evidência de sentido". Entendamos bem: o ponto de partida teórico (implícito) ressurge, de forma parafraseada, como se fosse o resultado da interpretação de dados supostamente desconhecidos. O corpus, destituído de sua função heurística, é usado como artifício retórico, oportunizando a explicitação de uma premissa sob a aparência da apresentação de um resultado. 


\section{Ainda não tem, mas já estamos vendendo...}

Resta perguntar o que possibilita que as falhas argumentativas apontadas na dissertação se tornem “invisíveis” aos olhos de uma comunidade acadêmica. Não nos parece suficiente afirmar que elas sejam negligenciadas por um simples efeito de assujeitamento ao discurso, já que, mesmo do ponto de vista expresso pelo pesquisador (assujeitado à forma-sujeito da teoria), esses resultados são inesperados e requerem uma série de explicações embaraçosas. Para responder a essa questão, vamos deslocar nosso ponto de vista e considerar o argumento básico de que os discursos podem ser pensados desde um ponto de vista econômico, como faz, por exemplo, Bourdieu (1998). Tomemos como base o ponto de partida deste autor: um enunciado linguístico recebe um "valor" conforme leis que não são as da língua, mas as de um mercado.

Sendo uma relação de comunicação entre um emissor e um receptor, fundada no ciframento e no deciframento, e portanto na operação de um código ou de uma competência geradora, a troca lingüística é também uma troca econômica que se estabelece em meio a uma determinada relação de força simbólica entre um produtor, provido de um dado capital linguístico, e um consumidor (ou um mercado), capaz de propiciar um certo lucro material ou simbólico. [...] Os discursos alcançam seu valor (e seu sentido) apenas através da relação com um mercado, caracterizado por uma lei especial de formação particular dos preços: o valor do discurso depende da relação de forças que se estabelece concretamente entre as competências linguísticas dos locutores, entendidas ao mesmo tempo como capacidade de produção, de apropriação e apreciação ou, em outros termos, como capacidade de que dispõem os diferentes agentes envolvidos na troca para impor os critérios de apreciação mais favoráveis a seus produtos. (BOURDIEU, 1998, p. 54)

Bourdieu tem em mente um processo de "apreciação” que ocorreria sobre as próprias formas linguísticas, determinando, por exemplo, a avaliação social que se faz de certos modos de pronúncia e outras diferenças “dialetais”. Consideremos, no entanto, que esse processo de "formação de preços" não pode ser determinado exclusivamente desde fora da língua, isto é, que as relações econômicas não são determinantes com relação à língua, mas dependem, elas mesmas, de relações linguísticas específicas. Assim, ainda que se recorra a um “dialeto” valorizado no mercado, ou ainda que se fale desde um lugar de prestígio (cultural ou econômico), não se pode dizer qualquer coisa. Para além de uma economia das formas linguísticas, o processo de apreciação dos enunciados deve envolver 
também a necessidade de se produzir certa coerência entre o que se diz e aquilo que se espera que seja dito desde determinado lugar. Desse modo, a apreciação de um discurso científico - que é o que estamos discutindo - não depende apenas de que ele seja enunciado "como um discurso científico" (usando-se termos técnico-científicos, construindo-se frases conforme certo padrão “formal” ou “dissertativo" etc.), mas também que diga coisas compatíveis com aquilo que se espera de um discurso científico (que se reconheça certo grau de objetividade e explicitude, que se percebam procedimentos interpretativos coerentes etc.).

Essa perspectiva nos leva a crer que o mercado deveria depreciar enunciados como os que encontramos na dissertação analisada antes, já que o próprio pesquisador reconhece que seus resultados frustram as expectativas produzidas pela teoria adotada. Dito de outra forma, os dados obtidos na pesquisa de campo ameaçam o "valor" dos enunciados usados para "capitalizar" o empreendimento inicialmente ${ }^{6}$. A comparação mais simples, ainda que um pouco grosseira, seria com o empresário que vai à bancarrota: dispondo-se de certas condições iniciais (dinheiro para investir na abertura de um negócio; acesso ao conhecimento científico que embasa a elaboração da pesquisa), aposta-se em uma determinada tendência do “mercado” (“o produto X vai ser um sucesso ano que vem”; “a teoria $Y$ vai mostrar que os alunos agem de tal e tal maneira”); ocorre, porém, que a tendência não se confirma (o produto $X$ se mostra um fiasco; os alunos demonstram agir de forma contraditória com o que preconiza a teoria Y). Em ambos os casos, suporíamos que o “capital” inicialmente investido se perde - fecha-se o negócio, modifica-se a teoria ou se engaveta a pesquisa.

Não é o que parece ter ocorrido. Podemos explicar esse comportamento imprevisto, em todo caso, se considerarmos que as leis do mercado não levam qualquer negócio à falência apenas porque ele deu prejuízo. Neste ponto vamos nos afastar de Bourdieu e levar em consideração algumas teses de Zizek (2011) sobre dois aspectos fundamentais do funcionamento de um “mercado”: os efeitos da especulação na produção de valores e a mediação do Estado na economia.

\footnotetext{
${ }^{6}$ É importante frisar que essa "frustração" não se dá na forma da refutação de uma hipótese (o que permitiria, em alguns casos, manter inalterada a teoria), mas no questionamento dos próprios pressupostos que caracterizam a teoria. O que está em jogo é em que medida "a perspectiva que confere primazia ao aluno" (isto é, a "avaliação formativa de tradição francófona”) de fato confere primazia ao aluno. Ou, dito de outra forma: em que medida a "avaliação formativa de tradição francófona" é mesmo a avaliação formativa de tradição francófona.
} 
Comecemos pela última: o Estado, segundo Zizek, age de forma a proteger o capital - não porque os governos sejam ideologicamente afinados com esse modelo econômico, mas porque uma crise do capital seria uma crise real que ameaçaria, na realidade, o modo de produção que sustenta a própria existência do Estado. A interveniência do Estado para proteger o capital especulativo, por sua vez, interfere nas próprias formas de especulação financeira possíveis dentro do mercado. Vejamos o que Zizek diz a respeito do comportamento dos banqueiros que, conforme a opinião pública geral, teriam sido os responsáveis pelo estouro da "bolha imobiliária” de 2009 ao emitir mais crédito do que tinham capacidade de pagar - lucrando bastante com isso -, e que foram salvos da falência por empréstimos do tesouro nacional (uma vez que a quebra sucessiva dos bancos colocaria a economia inteira em risco).

Essa [revolta do Partido Republicano contra a proposta de empréstimo do Fed aos bancos quebrados] não seria um caso óbvio do que a teoria econômica chama de "risco moral", definido como "o risco de que alguém se comporte de maneira imoral porque a seguradora, a lei ou outra instância qualquer o protegerá dos prejuízos que seu comportamento possa causar" - se tenho seguro contra incêndio, tomo menos cuidado (ou, in extremis, ponho fogo nas instalações que cobri com o seguro, mas que me dão prejuízo)? O mesmo vale para os grandes bancos: não estariam protegidos contra grandes perdas e não seriam capazes de manter o lucro? [...] Está claro que o erro de Greenspan não foi apenas e simplesmente ter superestimado a racionalidade dos agentes de mercado, isto é, sua capacidade de resistir à tentação de ter ganhos especulativos extraordinários. O que ele esqueceu de incluir na equação foi a perspectiva bastante racional dos especuladores de que valia a pena correr o risco, porque, no caso de um colapso financeiro, poderiam contar com o Estado para cobrir o prejuízo. (ZIZEK, 2011, p. 24/37)

Transpondo essa forma de pensar para o caso que nos interessa, deveríamos perguntar: de que maneiras o Estado pode estar exercendo um papel semelhante ao proteger a infraestrutura de pesquisa de um país e, indiretamente, a atividade “econômico”-especulativa de alguns indivíduos dos quais a continuidade das atividades científicas depende? Durão (2015), citando Richard Munch, afirma que, no chamado “modelo humboldtiano" de universidade, o "financiamento [à pesquisa] ocorre a priori, como um voto de confiança (Treuhänderschaft) de que os recursos empregados levarão a benefícios futuros” (DURÃO, 2015, p. 57). Parte-se do pressuposto de que os pesquisadores, sendo “intelectuais desinteressados”, visam em última instância a causas 
sociais ou epistemológicas que transcendem suas próprias condições subjetivas de existência enquanto empregados assalariados de uma empresa ou funcionários públicos. Mas não estaríamos também, à la Greenspan, nos esquecendo de colocar nas contas a inteligência do outro e considerar que, na medida em que se possa contar com esse Treuhänderschaft estatal - isto é, na medida em que a continuidade do financiamento à pesquisa deixa de depender do potencial direto de geração de "riquezas" materiais ou simbólicas dos seus resultados -, um grupo pode começar a apostar propositalmente em pesquisas improdutivas, obtendo com isso lucros (ainda que simbólicos) de natureza essencialmente especulativa, justamente por contar com o socorro do Estado (por exemplo, na forma da manutenção de seus empregos, inclusive sem reduções salariais) em caso de um total fracasso?

Essa questão nos parece fundamental para compreender como uma comunidade, pensada enquanto grupo "econômico”, pode inflacionar o valor de certos enunciados independentemente do "lastro" disponível no mercado. O quadro do atual "produtivismo" parece reunir duas condições suficientes para que isso aconteça. A primeira é o fato de que, desde que o aumento da produtividade acadêmica se torna uma meta em si mesma, o produto material de uma pesquisa deixa de ser seu potencial de aplicação a uma realidade exterior a ela (na forma da produção de uma técnica ou de uma compreensão do real) e passa a ser a própria realidade empírica do sistema universitário cuja produtividade se quer aumentar. A segunda condição é a relativa autonomia dada às comunidades acadêmicas para avaliar sua própria produtividade a partir do "voto de confiança” estatal (vivemos, ainda, sob um modelo essencialmente "humboldtiano" de universidade). Esta condição talvez tenha que ser aliada à lógica de setorialização das áreas que vêm se fortalecendo na gestão da pesquisa em nível institucional, fazendo com que decisões como os critérios de avaliação de originalidade e pertinência de uma pesquisa passem a ser tomadas por grupos relativamente pequenos de pessoas, capazes de empreender medidas de “manipulação de preços” baseadas em seu interesse mútuo em um setor do mercado.

Em sua forma extrema, essas medidas podem assumir a forma de um "esquema de Ponzi” gigantesco - como aquele que, segundo os comentários de Zizek, levou o empresário americano Bernie Madoff à prisão, mas que não é outra coisa senão uma aplicação extremamente ousada da lógica do próprio modo de produção capitalista 
(ZIZEK, 2011, p. 41 ss.). Traduzamos o “esquema de Ponzi” para o “mercado simbólico”: afirma-se que uma teoria vai produzir excelentes resultados; com isso, convence-se um grupo de pesquisadores a investir nela, adotando-a em suas aulas, publicando a seu respeito, orientando estudantes sobre a perspectiva etc. Depois de algum tempo, anunciase que essa teoria, “conforme esperado”, está gerando resultados extraordinários - do que é evidência a quantidade de pessoas que "já” a adotaram. Com isso se convencem mais pesquisadores a investir nela, incrementando o número de indivíduos ou grupos que se declaram filiados a ela - mencionando-a explicitamente nos títulos de seus trabalhos; citando seus autores mais representativos (mesmo que desnecessariamente); passando a usar termos que permitem identificá-los como membros da comunidade estudiosa da teoria, e assim por diante. Em algum momento, decide-se criar um congresso nacional de pessoas que trabalham com a teoria em questão, ou uma revista voltada para essa linha, o que aumenta os espaços disponíveis para a divulgação dos seus “bons resultados” - podese imaginar para onde vamos com esse exemplo.

O que nos interessa pontuar é que, na medida em que as próprias escolas muitas vezes estão apenas à margem do processo de produção de conhecimento sobre ensino de línguas na universidade (não participam das avaliações cegas por pares, não dispõem de uma produção acadêmica sólida o suficiente para contestar os resultados produzidos por outras instituições etc.), todo esse efeito em cascata pode acontecer sem que as realidades empíricas de ensino tomadas como objeto de pesquisa ${ }^{7}$ sejam modificadas de qualquer forma relevante pelas pesquisas realizadas sobre elas.

É nesse sentido que consideramos que o atual quadro reúne condições que permitem a certos grupos produzir, por meio de medidas essencialmente especulativas, uma percepção do que seja “originalidade” em pesquisa afinada às suas melhores possibilidades de lucro imediato. É também nesse sentido que acreditamos que, ao aproveitar esse "momento favorável do mercado", pode-se estar inflando uma "bolha” que em algum momento vai estourar. Aqui não estamos fazendo uma metáfora econômica - falamos ao pé da letra. A ausência de melhoras reais na qualidade da educação, produzidas pela pesquisa em Educação - incluímos aí todo o campo do ensino de línguas -, pode nos encontrar de cofres vazios quando as próximas gerações se apresentarem para

\footnotetext{
${ }^{7}$ Não estamos nos referindo apenas à produção de metodologias ou procedimentos de ensino, em um plano estritamente didático, mas também à produção de novas compreensões sobre as realidades de ensino de pontos de vista sociológicos, psicológicos, epistemológicos, éticos etc.
} 
sacar o crédito que estamos lhes dando hoje. Vai-se descobrir que a formação prestada em épocas de pujança, na forma de uma promessa de capacidade futura de trabalho, era uma letra de crédito vazia?

Com essas considerações, acreditamos responder às duas perguntas que lançamos inicialmente. O que é "produzir conhecimento" quando o objeto de pesquisa é o ensino de uma língua? Sob certas circunstâncias, ao menos, "produzir conhecimento” consiste em escrever de forma a constatar "performativamente" o sucesso de determinadas teorias (ou das posições políticas que subjazem a elas, das quais as próprias teorias são uma manifestação), valorando-as especulativamente e apostando na hipótese improvável de que os fracos resultados obtidos no ensino nunca afetarão as condições para que se continue fazendo pesquisa sobre ensino. De que forma as transformações recentes na universidade estão modificando também o regime de "conhecimento" até então vigente no campo do ensino de línguas? Enquanto o Estado sustentar um modelo "humboldtiano" de universidade, a produção de conhecimento “especulativo” (no sentido financeiro) pode continuar inchando índices de produtividade sem que se saiba, ao certo, qual é o aumento real das "riquezas” disponíveis - isto é, quais são os ganhos intelectuais e os avanços epistemológicos efetivamente realizados pela pesquisa universitária.

É bom lembrar, contudo, que esse modelo de universidade pode não durar muito e a transição para um paradigma neoliberal de Educação Superior, se acontecer, afetará mais intensamente aquelas áreas cujos produtos de pesquisa têm menor potencial de conversão em lucro financeiro. Será tanto pior se as pesquisas dessas áreas não tiverem gerado sequer lucros “simbólicos” que lhes permitam afetar significativamente as práticas sociais a que visam - pois nesse caso pode não restar quem erga a voz para lamentar o fim das pesquisas universitárias nas escolas.

Fiquemos, então, com as palavras de Zizek (2011, p. 24), que soam como interpelação do presente e aviso para o futuro. "É bem verdade que vivemos numa sociedade de escolhas arriscadas, mas apenas alguns têm a escolha, enquanto os outros ficam com o risco...”.

FAIRCHID, Thomas Massao. Production, productivism, plagiarism: notes on originality in language teaching research. Revista do Gel, v. 14, n. 1, p. 12-35, 2017. 


\begin{abstract}
We aim to contribute to the comprehension of contemporary university by analyzing how the "originality" idea is constructed in current research practices. We start by questioning plagiarism, sustaining that the recent debates on it in Brazil may point to an increasing tolerance for repetition by establishing the "right" ways to refer to past research results. We then give the problem of "originality" a theoretical treatment by revisiting M. Pêcheux's (1995) discussions on the "evidence of meaning" and the "preconstructed". Those concepts are used to analyze enunciates taken from a Masters' dissertation; they show that this research is organized in such a way as to protect the theoretical discourse "preconstructed" even when data contradict it. We ask how the work may be regarded as "original" under such circumstances. Our answer to that comes from an "economical" approach to the problem, based on Bourdieu's (1998) and Zizek's (2011) ideas. We pose that the value of "originality" in the context of a State-endorsed productivist policy, may be created through speculations of groups that have partial control over the "appreciation" of scientific enunciates.
\end{abstract}

Keywords: Production of knowledge. Productivism. Plagiarism. Market. Discourse analysis.

Submetido em: 19/06/2016.

Aceito em: 31/08/2016.

\title{
Referências
}

ALLOUCH, J. Letra a letra. Transcrever, traduzir, transliterar. Tradução de Dulce Duque Estrada. Rio de Janeiro: Campo Matêmico, 1995.

BOURDIEU, P. A economia das trocas lingüísticas. O que falar quer dizer. 2. ed. São Paulo: Editora da Universidade de São Paulo, 1998.

DUCROT, O. Pressupostos e subentendidos: a hipótese de uma semântica linguística. In: DUCROT, O. O dizer e o dito. Campinas: Pontes, 1987. p. 13-30.

DURÃO, F. A. Transformações na concepção de universidade, o caso brasileiro, e seus impactos nos estudos literários. Revista da ANPOLL, n. 38, p. 55-65, Florianópolis, jan.-jun. 2015.

FRANCHI, C. Mas o que é mesmo "gramática”? Com Esmeralda Vailati Negrão e Ana Lúcia Müller. Organizado por Sírio Possenti. São Paulo: Parábola Editorial, 2006.

KUHN, T. A estrutura das revoluções científicas. 2. ed. São Paulo: Perspectiva, 1978. (Coleção Debates)

PÊCHEUX, M. Semântica e discurso. Uma crítica à afirmação do óbvio. Tradução de Eni Puccinelli Orlandi et al. 2. ed. Campinas: Unicamp, 1995. 
REGO, T. C. Produtivismo, pesquisa e comunicação científica: entre o veneno e o remédio. Educação e Pesquisa, São Paulo, v. 40, n. 2, p. 325-346, abr.-jun. 2014.

ZIZEK, S. Primeiro como tragédia, depois como farsa. Tradução de Maria Beatriz de Medina. São Paulo: Boitempo, 2011. 